\title{
Letter
}

\section{Acute renal failure in patients with sepsis}

\author{
José António Lopes ${ }^{1}$, Sofia Jorge1, Cristina Resina1, Carla Santos², Álvaro Pereira², José Neves², \\ Francisco Antunes ${ }^{2}$ and Mateus Martins Prata ${ }^{1}$
}

\begin{abstract}
1Department of Nephrology and Renal Transplantation, Hospital de Santa Maria, Av. Prof. Egas Moniz, 1649-035, Lisboa, Portugal ${ }^{2}$ Department of Infectious Diseases, Hospital de Santa Maria, Av. Prof. Egas Moniz, 1649-035, Lisboa, Portugal
\end{abstract}

Corresponding author: José António Lopes, jalopes93@hotmail.com

Published: 19 April 2007

This article is online at http://ccforum.com/content/11/2/411

(C) 2007 BioMed Central Ltd
Critical Care 2007, 11:411 (doi:10.1186/cc5735)

were analyzed. Baseline characteristics of the patients are summarized in Table 1. Sixty-eight patients (37.4\%) had ARF. By multivariate analysis, age more than 60 years (odds ratio (OR) 0.39, 95\% confidence interval (Cl) 0.17 to 0.87 , $P=0.002$ ), male (OR 5.5, 95\% Cl 2.2 to $13.5, P<0.0001$ ), chronic kidney disease (OR $0.2,95 \% \mathrm{Cl} 0.06$ to 0.79 , $P=0.021$ ), Gram-negative-related infection (OR 0.38, 95\% $\mathrm{Cl} 0.16$ to $0.89, P=0.027$ ), and a Simplified Acute Physiology Score, version II (SAPS II) > 50 (OR 0.14, 95\% Cl 0.06 to $0.31, P<0.0001)$ were independently associated with ARF. Thirteen patients ( 3 with injury and 10 with renal failure) had received renal replacement therapy (12 receiving continuous venovenous hemodiafiltration, and 1 receiving

Table 1

\begin{tabular}{|c|c|c|c|c|c|}
\hline Variable & No AKI & Risk & Injury & Failure & $P$ \\
\hline$n$ & 114 & 11 & 21 & 36 & \\
\hline Age (years)a & $54 \pm 18.2$ & $61.9 \pm 20.9$ & $61.6 \pm 13.4$ & $61.8 \pm 16.3$ & NS \\
\hline Sex (male) & $65(57)$ & $10(91)$ & $18(85.7)$ & $27(75)$ & 0.009 \\
\hline Race (Caucasian) & $102(89.5)$ & $10(91)$ & $20(95.2)$ & 30 (83.3) & NS \\
\hline Severe sepsis ${ }^{b}$ & $77(67.5)$ & $6(54.5)$ & $12(57.1)$ & $13(36.1)$ & 0.012 \\
\hline Septic shock ${ }^{b}$ & $25(21.9)$ & $4(36.4)$ & $8(38)$ & $23(64)$ & $<0.0001$ \\
\hline CVD & $37(32.4)$ & 3 (27.3) & $10(47.6)$ & $14(38.9)$ & NS \\
\hline CKD & $5(43.9)$ & $1(9)$ & $4(19)$ & $8(22.2)$ & 0.009 \\
\hline SAPS $\|>50$ & $22(19.3)$ & $6(54.5)$ & 7 (33.3) & $9(26.5)$ & 0.06 \\
\hline Mortality & $11(9.6)$ & $3(27.3)$ & $6(28.6)$ & $20(55)$ & $<0.0001$ \\
\hline
\end{tabular}

Figures in parentheses are percentages. AKI, acute kidney injury; CKD, chronic kidney disease; CVD, cardiovascular disease, diabetes mellitus and hypertension; NS, not significant; SAPS II, Simplified Acute Physiology Score, version II. The SAPS II was calculated on the basis of the worst variables recorded during the first 24 hours of ICU admission. aMeans \pm SD; b sepsis was classified in accordance with American College of Chest Physicians and the Society of Critical Care Medicine consensus [2].

$\mathrm{ARF}=$ acute renal failure; $\mathrm{Cl}=$ confidence interval; $\mathrm{OR}=$ odds ratio; RIFLE = risk, injury, failure, loss, end-stage kidney disease; SAPS $\|=$ Simplified Acute Physiology Score, version II. 
intermittent hemodialysis). The mortality rate was $37.4 \%$, and increased from 'normal' to 'failure'. Patients who did not die had renal function recovery. Multivariate analysis including age more than 60 years, gender, SAPS II $>50$, comorbidity (namely cardiovascular disease), and ARF showed that SAPS II $>50$ (OR 0.12, 95\% Cl 0.05 to $0.29, P<0.0001$ ) and ARF (OR $0.26,95 \% \mathrm{Cl} 0.11$ to $0.63, P=0.003$ ) were independent predictors of mortality.

Thus, ARF as determined by RIFLE is common among patients with sepsis, and increases mortality. Age, gender, chronic kidney disease, Gram-negative-related infection and severity of illness are independently associated with ARF in this setting.

\section{Authors' contributions}

JAL, SJ, CR, and CS made substantial contributions to the conception and design of the study, to the acquisition of data, and to the analysis and interpretation of data. JAL, CR, $A P, J N, F A$, and MMP were involved in drafting the manuscript and revising it critically for important intellectual content. All authors read and approved the final manuscript.

\section{Competing interests}

The authors declare that they have no competing interests.

\section{References}

1. Bellomo R, Ronco C, Kellum JA, Mehta, RL, Palevsky P and the ADQI workgroup: Acute renal failure - definition, outcome measures, animal models, fluid therapy and information technology needs: the Second International Consensus Conference of the Acute Dialysis Quality Initiative (ADOI) Group. Crit Care 2004, 8:R204-R212.

2. Levy MM, Fink MP, Marshall JC, Abraham E, Angus D, Cook D, Cohen J, Opal SM, Vincent JL, Ramsay G; SCCM/ESICM/ACCP/ ATS/SIS: 2001 SCCM/ESICM/ACCP/ATS/SIS International Sepsis Definitions Conference. Crit Care Med 2003, 4:12501256. 